\title{
ESTIMATION AND INFERENCE IN COINTEGRATED DEMAND SYSTEMS: AN APPLICATION TO TUNISIAN MEAT CONSUMPTION
}

\author{
M. BEN KAABIA \\ Department of Economic Analysis \\ University of Zaragoza (Spain)
}

J.M. GIL ${ }^{1}$

\author{
Unidad de Economía Agraria, SIA-DGA \\ Zaragoza (Spain)
}

\begin{abstract}
In this paper, a new framework for estimating and identifying cointegrated demand systems is presented. This method is then applied to the analysis of meat demand in Tunisia with an Almost Ideal Demand system functioning as the underlying model. The Johansen and Juselius approach is used to identify cointegrated vectors as demand equations and to test theoretical economic restrictions. Finally, a structural VAR model is specified and impulse response functions are calculated to analyse both long and short-run dynamics of demand elasticities.
\end{abstract}

Key words - Almost Ideal Demand system, cointegration, meat demand, Tunisia, long-run identification, impulse response functions.

1 Corresponding author. Unidad de Economía Agraria, SIA-DGA. Apdo 727; 50080Zaragoza (Spain). Email: jmgil@ posta.unizar.es 


\section{ESTIMATION AND INFERENCE IN COINTEGRATED DEMAND SYSTEMS: AN APPLICATION TO TUNISIAN MEAT CONSUMPTION}

\section{Introduction}

Food demand analysis is a topic that has recently generated great interest among agricultural economists given its usefulness in food policy and marketing decisions. However, only a few studies have been carried out in Tunisia on food demand. Fuglie (1994) analysed the demand for potatoes as a substitute of cereals, while Lahiani (1996) focused on the demand for oils. Also, the Institut National de la Statistique (National Statistics Institute or INS, 1995) published income elasticities for selected food products. Finally, Dhehibi (1998) estimated two demand systems to analyse the demand for aggregated food categories and for meat products.

The analysis of the demand for meat products in Tunisia is especially relevant. First, meat products have the largest share of total food expenditure, accounting for almost 25 per cent. Second, meat products, together with fish and fruits and vegetables are not subsidised ${ }^{1}$; that is, retail prices are determined by market forces, generating an increased need for demand analyses of these products. Finally, with the exception of Dhehibi (1998), no attempt has been made to estimate meat demand elasticities in Tunisia.

The Almost Ideal Demand (AID) system (Deaton and Muellbauer, 1980) has emerged as an important vehicle for the empirical analysis of consumer behaviour due to its desirable properties. Demand systems that are consistent with utility maximisation should satisfy three general restrictions: homogeneity, symmetry and concavity. However, the application of the AID model has been somewhat disappointing due to the frequent rejection of the

\footnotetext{
${ }^{1}$ In Tunisia, most food products have traditionally been subsidised for food security reasons. During the 70 s and early 80 s, food subsidies were an increasing proportion of public expenditure. Universal subsidies were criticised as they mostly benefited the wealthier segment of the population. Following the 1986 Structural Adjustment Program, food policy changed. A self-targeted program was implemented in 1990 in which selected food products consumed by the population with the lowest income level were subsidised. Subsidies on meat products disappeared, although they were already very low before that date.
} 
homogeneity and symmetry restrictions in a number of applied studies ${ }^{2}$. Usually, dynamics have been incorporated into demand systems in order to deal with the over-rejection of these restrictions.

Introduction of dynamic components in demand analysis is not new. Brown (1952) justified the introduction of lags in demand equations, assuming that consumers' reactions to changes in income and prices took place gradually. Even Deaton and Muellbauer (1980) suggested estimating the AID model in first differences so as to account for habit persistence. Anderson and Blundell $(1983,1984)$ proposed a general framework to tackle dynamics. They specified an AID model in an error correction formulation, which nested other alternative dynamic specifications that had been used in the current literature, showing that demand restrictions were accepted by the data in the long run.

Recent developments in non-stationary time series and cointegration techniques have opened an alternative approach for introducing dynamics into demand systems. When non-stationary variables are used, homogeneity and symmetry tests, carried out on the estimated system in level form using least squares, are no longer valid. On the other hand, if the variables are cointegrated, the specification of a demand system in first differences is biased due to the misspecification of the long-run relationships. Thus, the estimation of cointegrated demand systems has become increasingly popular (see, for instance Denbaly and Vroomen, 1993; Balcombe and Davis, 1996; Attfield, 1997; and Chambers and Nowman, 1997).

The estimation of an error correction AID model is routinely carried out using Engle and Granger's (1987) (EG) two-step procedure. This approach, however, has been criticised for the following reasons: i) in the specification of the system only budget shares are classified as endogenous variables, while prices and real expenditure are assumed a priori to be weakly exogenous; ii) the number of cointegrating vectors is generally assumed to be equal to the number of estimated equations; and iii) from the first criticism, price indices and real expenditure assumed to be individually non-cointegrated.

\footnotetext{
${ }^{2}$ The semi-definite negativeness of the Slutsky matrix (concavity requirement) cannot be tested by imposing linear restrictions. However, results should be examined to check if this assumption holds. If it does not hold, Moschini (1998) has developed methods for imposing it.
} 
An alternative framework for estimating a demand system with non-stationary variables was first suggested in a seminal paper by Johansen (1988). This approach has the advantage that it does not depend on an arbitrary division of the variables as endogenous or exogenous, and that the number of long-run relationships is not assumed a priori but can be explicitly tested. Additionally, Gonzalo (1994) suggested that Johansen's procedure is more robust than the EG approach in terms of capturing long-run relationships not found by the EG procedure ${ }^{3}$. Pesaran and Shin (1999) used this same approach to estimate a cointegrated demand system in order to provide an example of how to carry out tests across cointegrating vectors (the symmetry restriction). In their study, considering three goods, they identified two cointegrating vectors, which corresponded exactly to the number of estimated equations in the AID model taking into account the adding-up restriction. However, this is not always the case.

The aim of this paper is to provide an example of how to estimate a cointegrated AID model nested in a Vector Error Correction Model, assuming all variables in the system are endogenous, for the case when the number of cointegrating relationships exceeds the number of estimated equations.

To achieve the above-mentioned objective, this article is organised as follows. Since we are dealing with meat demand in Tunisia, the next section briefly describes its evolution in the last twenty years. Section 3 is devoted to a description of the Johansen and Juselius procedure and the way it can be applied to food demand analysis. The data and main results are described in section 4. Finally, we end with some concluding remarks.

\section{The Evolution of Meat Consumption in Tunisia}

Since the early 1980s the eating habits of Tunisians have significantly changed, with an increasing demand for products of animal origin. Animal-based calorie intake has grown

\footnotetext{
${ }^{3}$ On the other hand, it is important to note that the application of the Johansen procedure to the estimation and testing of cointegrated demand systems is not straightforward. In some cases, when the number of products considered is 4 or 5, it is difficult to get any kind of convergence when over-identifying restrictions are imposed. We gratefully acknowledge the comment made by an anonymous referee on this point.
} 
continuously to a 1997 level of around 12 per cent of total calorie intake (FAO database). According to the statistics of the Tunisian Ministry of Agriculture, per capita consumption of meat evolved from about 14.5 to $19.4 \mathrm{~kg} / \mathrm{capita} /$ year during the period 1973-1998, representing the highest increase of any other North African country. Nevertheless, the level of meat consumption in Tunisia is still very low in relation to Northern Mediterranean countries (around $65 \mathrm{~kg} / \mathrm{capita} / \mathrm{year}$ ), bearing in mind that in the case of Arab countries the consumption of pork is almost zero). Table 1 shows Tunisia's annual per capita consumption of beef (including veal), lamb, and poultry. There has been a significant increase in poultry consumption while beef and lamb consumption have fluctuated considerably. In any case, during the 1990s, all meats showed an upward trend, which can be related to the general economic upswing that has taken place in Tunisia since the implementation of the Structural Adjustment program in 1986.

(Insert Table 1)

Concerning expenditure levels, Tunisia has followed quite closely the pattern of a typical developing country. Food expenditure still represents a considerable proportion of household income. In 1975 food expenditure represented 41 per cent of total expenditure, while in 1995 this figure decreased slightly to 38 per cent (INS, 1995). The only products that have experienced an increase in their relative importance are meat and fish. In 1995, meat products accounted for 25 per cent of total food expenditure. Focusing on only meat expenditure, Tunisians spent 41 per cent on beef, 42 per cent on lamb and 17 per cent on poultry.

Since 1986 prices have increased significantly in nominal terms, although, in relative terms, no major changes have been observed. The absolute price increase is due to the removal of meat subsidies when the Tunisian government implemented the Structural Adjustment Program to stimulate Tunisian economy, at that time in deep recession. On average, the most expensive products are lamb and beef, whose prices are very similar. Poultry prices have always been lower than those of other meats.

\section{Methodological Framework}

3.1 The AID Model and Cointegration Implications 
A number of demand systems have been used to explain how food expenditure is allocated among different foods. The AID model is the most commonly used because of its desirable features and ease of estimation, especially in the linearised version using Stone's price index. Moreover, both the homogeneity and symmetry restrictions can be imposed by applying linear restrictions on the estimated parameters. The static AID model in budget share terms is defined as follows:

$w_{i t}=\alpha_{i}+\beta_{i} \log \left(\frac{y_{t}}{P_{t}}\right)+\sum_{j}^{n} \gamma_{i j} \log p_{j t}+u_{i t}$

where $\mathrm{w}_{\mathrm{it}}$ is the average budget share of the $\mathrm{i}$-th good in period $\mathrm{t}, \mathrm{y}_{\mathrm{t}}$ is the total expenditure, $\mathrm{p}_{\mathrm{jt}}$ represents the price of the $\mathrm{j}$-th good and $\mathrm{P}_{\mathrm{t}}$ is a price index (such as $P_{t}=\exp \left(\sum_{j}^{n} \overline{w_{j}} \log p_{j}\right)$, all in period $\mathrm{t}(\mathrm{t}=1 \ldots . \mathrm{T})$. Adding-up requires that $\sum_{i=1}^{n} \alpha_{i}=1, \sum_{i}^{n} \beta_{i}=0$ and $\sum_{i=1}^{n} \gamma_{i j}=0$. The (n-1) homogeneity and the $\mathrm{n}(\mathrm{n}-1) / 2$ symmetry restrictions can be expressed as $\sum_{j=1}^{n} \gamma_{i j}=0$ and $\gamma_{i j}=\gamma_{j i}$, respectively.

The Marshallian price $\left(\varepsilon_{\mathrm{ij}}\right)$ and expenditure $\left(\eta_{\mathrm{i}}\right)$ elasticities at mean values of the budget shares $\left(\bar{w}_{\mathrm{i}}\right)$ are given by:

$$
\begin{aligned}
& \varepsilon_{i j}=-\delta_{i j}+\frac{\gamma_{i j}-\beta_{i} \bar{w}_{j}}{\bar{w}_{i}} \\
& \eta_{i}=\frac{\beta_{i}}{\bar{w}_{i}}+1
\end{aligned}
$$

where $\delta_{\mathrm{ij}}$ is the Kronecker delta, which is equal to 1 when $\mathrm{i}=\mathrm{j}$ and 0 , otherwise. The Hicksian compensated price elasticities are given by:

$$
\varepsilon_{\mathrm{ij}}^{*}=-\delta_{\mathrm{ij}}+\frac{\gamma_{\mathrm{ij}}}{\overline{\mathrm{w}}_{\mathrm{i}}}+\overline{\mathrm{w}}_{\mathrm{j}}
$$

If the series in model (1) are non-stationary and cointegrated, then the system reveals a longrun utility-maximising consumption pattern for meat products. However, the application of Ordinary Least Squares to the system (1) results in parameter estimates which are superconsistent but have non-standard distributions, making it impossible to test whether the theoretical restrictions hold, since tests based on standard asymptotic results will have the 
wrong size ${ }^{4}$. Alternative techniques for estimation and inference in the case of long-run equilibrium relationships have been developed (see for example Stock and Watson 1993; Johansen, 1988; Phillips and Hansen, 1990; Johansen and Juselius 1992; Park, 1992). However, the cointegration approach has only been applied quite recently to demand analysis. $\mathrm{Ng}$ (1995) and Attfield (1997) specified a system of variables in triangular form, estimating the system using Dynamic Ordinary Least Squares (Stock and Watson, 1993) and testing homogeneity with a Wald statistic. Balcombe and Davis (1996) used the canonical cointegrating regression (CCR) (Park, 1992) to estimate an AID system for food consumption in Bulgaria. In all these papers, no attempt was made to identify the cointegrating relationships. It was assumed a priori that among the $(2 \mathrm{n}+1)$ variables ( $\mathrm{n}$ budget shares, $\mathrm{n}$ prices and real expenditure) there were $n-1$ cointegrating vectors each of which corresponds exactly to an equation of the system ${ }^{5}$. Recently, Pesaran and Shin (1999) estimated a cointegrated AID model using the Johansen procedure. They found exactly $n-1$ cointegrating relationships among the variables. They included both the exact identification restrictions (on budget share variables) and the over-identification restrictions (homogeneity and symmetry) on the cointegrating vectors so as to specify a long-run AID model compatible with economic theory.

However, it is possible that the number of cointegrating vectors exceeds $n-1$. In this case other alternatives may exist. A simple example is provided to illustrate this point. Let us assume that, as in many empirical applications, all the variables in the AID model are I(1). The empirical counterpart of (1) can be written as a cointegrating relationship:

$\mathrm{w}_{\mathrm{it}}-\alpha_{\mathrm{i}}-\beta_{\mathrm{i}} \log \left(\frac{\mathrm{y}_{\mathrm{t}}}{\mathrm{P}_{\mathrm{t}}}\right)-\sum_{\mathrm{j}}^{\mathrm{n}} \gamma_{\mathrm{ij}} \log \mathrm{p}_{\mathrm{jt}}=\mathrm{u}_{\mathrm{it}}$

where $\mathrm{u}_{\mathrm{it}}$ is the disequilibrium error associated with the $\mathrm{i}$-th equation of the AID model.

Suppose that prices are cointegrated, that is, a linear combination among them is $\mathrm{I}(0)$ (this is not an unrealistic assumption since prices are often assumed to be driven by a common

\footnotetext{
${ }^{4}$ Moreover, in the elasticity equations, the use of average budget shares would not be possible unless such series contained a random walk without drift. Otherwise, the unconditional mean is not constant. Pesaran and Shin (1999) converted all data into indices to ensure that the estimates of $\alpha$ 's in (1) are close to the budget shares in the base year and used the resulting estimate to calculate demand elasticities.

${ }^{5}$ One equation is arbitrarily deleted due to the adding-up restriction.
} 
stochastic shock to inflation, for instance). Under the previous assumptions, the long-run structure of a demand system can be identified by considering the following path:

$$
\begin{aligned}
& \mathrm{w}_{\mathrm{it}}-\beta_{\mathrm{i}} \log \left(\frac{\mathrm{y}_{\mathrm{t}}}{\mathrm{P}_{\mathrm{t}}}\right)+\sum_{\mathrm{j}}^{\mathrm{n}} \gamma_{\mathrm{ij}} \log \left(\mathrm{p}_{\mathrm{jt}}\right)=\mathrm{u}_{\mathrm{it}} \sim \mathrm{I}(0) \quad(\mathrm{I}=1, \ldots, \mathrm{n}-1) \\
& \sum_{\mathrm{i}}^{\mathrm{n}} \delta_{\mathrm{i}} \ln \left(\mathrm{p}_{\mathrm{it}}\right)=\mathrm{u}_{\mathrm{nt}} \sim \mathrm{I}(0)
\end{aligned}
$$

In (3), $n$ cointegrating vectors are assumed to exist. The $n-1$ first cointegrating vectors are identified as structural long-run AID equations where theoretical restrictions are imposed (homogeneity). In the extra cointegrating vector, exclusion restrictions are imposed on budget shares and real expenditure (i.e. prices are cointegrated) although other exclusion restrictions could be considered (on prices, etc.). It is important to note, however, that if the homogeneity restrictions are used as identifying restrictions for the n-1 AID equations, then, in the price cointegrating relationship such a homogeneity restriction should not be imposed. In other words, restrictions used to identify one equation should not be applied to the other in order to satisfy the rank condition.

This framework is now applied to an AID model, but it can easily be generalised to other functional forms. The following steps are followed. After testing for unit roots, the number of existing cointegrating relationships among all non-stationary variables is tested using Johansen's (1988) procedure. Second, taking into account the results from the previous step, several restrictions are imposed on the cointegrating vectors in order to identify them. Once the long-run behaviour is analysed, short-run dynamics are considered. Impulse response functions are calculated, showing the response of demand elasticities to shocks in real income and prices.

\subsection{The Johansen and Juselius Approach}

As mentioned above, in this paper the Johansen and Juselius procedure is used to properly specify and estimate a cointegrated AID model. We now explain the main steps in this procedure. The starting point is the specification of the following Vector Error Correction Model (VECM): 
$\Delta \mathrm{Y}_{\mathrm{t}}=\mu \mathrm{D}_{\mathrm{t}}+\Gamma_{1} \Delta \mathrm{Y}_{\mathrm{t}-1}+\ldots+\Gamma_{\mathrm{q}-1} \Delta \mathrm{Y}_{\mathrm{t}-\mathrm{q}+1}-\Pi \mathrm{Y}_{\mathrm{t}-1}+\mathrm{e}_{\mathrm{t}}$

where $Y_{t}$ is a $k \times 1$ column vector made up of budget shares (less one, which is arbitrarily deleted to overcome the singularity of the system due to the adding up restriction), prices and real expenditure, $D_{t}$ is a vector of deterministic variables (intercepts, trend,..), $\mu$ is the matrix of parameters associated with $D_{t}, \Gamma_{i}$ are $k \times k$ matrices of short-run parameters $(i=1, \ldots, q-1)$, with q representing the number of lags, $\Pi$ is a $\mathrm{k} \times \mathrm{k}$ matrix of long-run parameters and $\mathrm{e}_{\mathrm{t}}$ is the vector of disturbances which follow identical and independent normal distributions with zero mean and $\mathrm{E}\left(\mathrm{e}_{\mathrm{t}} \mathrm{e}_{\mathrm{t}}{ }^{\prime}\right)=\Sigma$.

If the series in $Y_{t}$ are integrated of order one, the right and left hand sides in (4) will be balanced only if the series are cointegrated. In other words, the rank (r) of the cointegrating (П) matrix must be strictly less than $\mathrm{k}$. To test for the number of cointegrating vectors (r), Johansen (1988) proposed two statistics: the trace statistic (which tests whether there are $r$ cointegrating vectors against the null hypothesis $(\operatorname{rank}(\Pi) \leq \mathrm{k})$ ); and the $\lambda_{\max }$ statistic (which tests whether there are $r$ cointegrating vectors against the alternative $r=r+1$ ). If the hypothesis of cointegration is not rejected, the cointegrating matrix can be decomposed into the product of two $k \times r$ matrices $\left(\Pi=\alpha \beta^{\prime}\right)$. The parameters of the $\alpha$ matrix represent the speed of adjustment to disequilibrium after a shock in the long-run relationships, while $\beta$ is a matrix of long-run coefficients such that the term $\left(\beta^{\prime} Y_{t-1}\right)$ represents the (r) long-run steady-state solutions.

However, when $r>1$ the estimated coefficient matrices $\alpha$ and $\beta$ are not necessarily uniquely determined, since any linear combination of stationary vectors is also a stationary relationship and consequently an economic interpretation of the cointegrating vectors is not possible. In those cases, the economic interpretation of the cointegrating vectors as structural long-run relationships requires the imposition of at least $r^{2}$ restrictions ( $r$ of which are provided by normalisation conditions) on the cointegration space. These restrictions can be motivated by economic arguments (e.g. that a particular variable does not appear in a particular vector, or the homogeneity or/and symmetry restrictions). Johansen and Juselius (1994) and Johansen (1995a) developed a testing procedure to identify the cointegrating vectors by imposing linear restrictions on them. Doornik (1995) and Pesaran and Shin (1999) generalised this procedure, allowing for the imposition of non-linear restrictions. 
On the other hand, it is sometimes of interest to test joint restrictions on both the cointegration vectors and the adjustment coefficients. Johansen and Juselius (1992) developed a procedure to carry out individual tests on parameters from both matrices ${ }^{6}$. Following Mosconi (1998), the model (4) can be estimated under rather general linear restrictions on both the long-run parameters, $\alpha$ and $\beta$. A general formulation of the null hypothesis can be expressed as:

$$
\begin{aligned}
& \mathrm{H}_{0}: \beta=\left[\beta_{1} \ldots \beta_{\mathrm{r}}\right]=\left[\mathrm{K}_{1} \varphi_{1} \ldots \mathrm{K}_{\mathrm{r}} \varphi_{\mathrm{r}}\right] \\
& \alpha=\left[\alpha_{1} \ldots \alpha_{\mathrm{r}}\right]=\left[\mathrm{A}_{1} \mathrm{a}_{1} \ldots \mathrm{A}_{\mathrm{r}} \mathrm{a}_{\mathrm{r}}\right]
\end{aligned}
$$

where $K_{j}$ is a $\mathrm{k} \times \mathrm{s}_{\mathrm{j}}$ matrix defining linear restrictions that reduce the k-dimensional vector $\beta_{\mathrm{j}}$ to the $s_{j}$-dimensional vector $\varphi_{j}$, with $s_{j}$ representing the number of unrestricted parameters in $\beta_{\mathrm{j}}, \mathrm{k}_{\mathrm{j}}$ is the number of restricted parameters in $\beta_{\mathrm{j}}$, such that $\mathrm{k}_{\mathrm{j}}+\mathrm{s}_{\mathrm{j}}=\mathrm{k}$; similarly, $\mathrm{A}_{\mathrm{i}}$ are $\left(\mathrm{k} \times \mathrm{f}_{\mathrm{i}}\right)$ restriction matrices $\alpha_{i}^{\prime} s, f_{i}$ being the number of unrestricted parameters in $\alpha_{i}$.

Note that when $\alpha$ is not restricted $\left(A_{i}=I\right),(5)$ can be used to test the identification restrictions on $\beta$. As shown in Johansen (1995a), inference on the coefficients of cointegrated VAR systems is asymptotically based on mixed Gaussian distributions, so the likelihood ratio statistic for testing the hypothesis (5) is asymptotically $\chi^{2}$. Unfortunately, when restrictions on both $\alpha$ and $\beta$ are jointly considered, no general formula has been derived yet to compute the degrees of freedom of the test, although they are easily computed in many cases, as shown in Mosconi (1998).

\section{The Empirical Estimation of Meat Demand in Tunisia}

\subsection{Data and Non-stationarity}

Data for this study comes from various sources. The information representing quantities consumed has been obtained from Food Balance Sheets published by the Ministry of

\footnotetext{
${ }^{6}$ The general procedure is to test restrictions on $\beta$ parameters and afterwards on $\alpha$ coefficients with the restrictions on $\beta$ imposed.
} 
Agriculture in Tunisia. Annual price series for each commodity were extracted from the Bulletin Mensuel de Statistique (Monthly Statistical Bulletin) published by the Institut National de la Statistique (National Statistics Institute, or INS). We have decided to consider beef, lamb and poultry. Fish is not included since Dhehibi (1998) found that fish and meat products were separable in Tunisia. Data are annual covering the period from 1973 to 1998.

Before implementing the Johansen and Juselius procedure, the order of integration of each variable in the system (budget shares, prices and real expenditure for meat) is tested. The Augmented Dickey-Fuller test $(\mathrm{ADF})^{7}$ is implemented following a sequential procedure explained in Harris (1995) in which special attention is paid to the lags and deterministic components included in the model. Results indicate that we cannot reject the hypothesis that all variables are I(1), using a 5 per cent level of significance (Table 2$)^{8}$.

(Insert Table 2)

\subsection{Cointegration Analysis}

\section{Cointegrating rank}

A six-variable VECM is specified (two budget shares, three prices and the real expenditure for meat). For this modelling framework to become operational, we have to determine the lag order (q), the deterministic components to be introduced in the model and the cointegrating rank (r). The initial VECM in (4) was specified with the constant terms restricted to the cointegration space ${ }^{9}$. However, based on the Akaike Information Criterion (AIC) and the likelihood ratio test (Tiao-Box, 1981), a VECM with two lags is chosen. As a first check of the statistical adequacy of the model, multivariate misspecification tests have been computed.

\footnotetext{
${ }^{7}$ The KPSS (Kwiatkowski et al., 1992) test also gives the same results.

${ }^{8}$ Budget shares are bounded between 0 and 1, so they are expected to be stationary in the long run. However, in our case, the variables show the typical characteristics of I(1) variables (sample autocorrelation coefficients are over 0.9 till the sixth lag). As a result, we consider them to be non-stationary. A similar approach is used in $\mathrm{Ng}$ (1995), Attfield (1997) and Pesaran and Shin (1999).

${ }^{9}$ According to the results in table 1 , the hypothesis that $\mathrm{E}\left[\Delta \mathrm{Y}_{\mathrm{t}}\right]=0$ cannot be rejected for all budget shares and real expenditure, indicating that there is no evidence of a linear trend in the data. In any case, following Harris (1995) several tests (subject to the rank restriction on the long-run matrix $\Pi$ ) have been conducted to empirically select the deterministic component introduced in the model. Results clearly indicate that a model with a restricted constant is statistically preferred.
} 
The Godfrey (1988) multivariate autocorrelation and the Doornik and Hansen (1994) multivariate normality tests indicated that the model with two lags was appropriately specified (34.32 and 10.72, with critical values of 50.71 and 21.03, respectively, at the 5 per cent level $)^{10}$.

Table 3 shows both the trace and the maximum eigenvalue $(\lambda$-max) statistics. As can be observed, both tests indicate the presence of three cointegrating relationships. However, as many previous simulation studies have demonstrated, asymptotic distributions are often poor approximations for small sample distributions. Thus, the results from both tests have to be interpreted with some caution. Juselius (1999) proposes an alternative approach in which she tests the significance of the adjustment coefficients for the $r$-th cointegrating vector $\left(\alpha_{i r}\right)$. If all $\alpha_{\text {ir }}$ coefficients are non-significant, then the cointegration rank should be reduced to (r-1). In our case, four of the estimated adjustment coefficients for the third cointegrating vector were significant, indicating that we had more cointegrating vectors than estimated equations. After normalisation, the three estimated cointegrating vectors have the following form:

$$
\begin{aligned}
& \mathrm{w}_{\mathrm{bt}}+0.210 \mathrm{w}_{\mathrm{lt}}-0.220 \mathrm{LP}_{\mathrm{bt}}+0.25 \mathrm{LP}_{\mathrm{lt}}-0.075 \mathrm{LP}_{\mathrm{pt}}-0.084 \mathrm{LRE}_{\mathrm{t}}-0.726=\mathrm{u}_{1 \mathrm{t}} \\
& 0.800 \mathrm{w}_{\mathrm{bt}}+\mathrm{w}_{\mathrm{lt}}+0.101 \mathrm{LP}_{\mathrm{bt}}-0.110 \mathrm{LP}_{\mathrm{lt}}+0.016 \mathrm{LP}_{\mathrm{pt}}-0.024 \mathrm{LRE}_{\mathrm{t}}-0.829=\mathrm{u}_{2 \mathrm{t}} \\
& -32.44 \mathrm{w}_{\mathrm{bt}}-33.75 \mathrm{w}_{\mathrm{lt}}+\mathrm{LP}_{\mathrm{bt}}-0.89 \mathrm{LP}_{\mathrm{lt}}+0.126 \mathrm{LP}_{\mathrm{pt}}+4.09 \mathrm{LRE}_{\mathrm{t}}+16.737=\mathrm{u}_{3 \mathrm{t}}
\end{aligned}
$$

where $\mathrm{w}$ denotes a budget share, LP is the log of price, LRE is the log of real expenditure and the subscripts b, 1 and $p$ refer to beef, lamb and poultry, respectively.

\section{(Insert Table 3)}

Given that the number of cointegrating vectors is greater than the number of goods included in the system, a two-step procedure is used to check whether the hypothesis (3a) presented in section 3 is supported by the data. In the first step, each single cointegrating vector is tested for stationarity leaving the other two vectors unrestricted (see Table 4). The second step consists of testing the joint hypothesis of full identification, which will be considered in the next section. The first three hypotheses $\left(\mathrm{H}_{1}-\mathrm{H}_{3}\right)$ in Table 4 formally test whether real

\footnotetext{
${ }^{10}$ A more parsimonious model $(q=1)$ was also estimated but specification tests clearly indicate that the model was misspecified.
} 
expenditure and the two budget shares are I(0) around a non-zero mean (we are simply rechecking results from unit root tests). Hypotheses $\left(\mathrm{H}_{4}\right)$ test whether the three prices are cointegrated. Finally, the hypotheses that each AID equation with homogeneity imposed is a stationary relationship have not been tested as the degrees of freedom are zero; thus the tests do not apply ${ }^{11}$. These hypotheses are of the form $\beta=(\mathrm{K} \phi, \psi)$, where restrictions are tested on a single cointegrating vector, leaving the other two unrestricted (for further details see Johansen and Juselius, 1992). As expected, the null hypotheses of stationarity for each budget share and real expenditure $\left(\mathrm{H}_{1}-\mathrm{H}_{3}\right)$ are clearly rejected ${ }^{12}$. Finally, the hypothesis $\mathrm{H}_{4}$ cannot be rejected at the 5 per cent significance level indicating that the three prices are cointegrated.

(Insert Table 4)

Long-run structural modelling

The VECM that takes into account two lags and three cointegrating vectors has the following form:

$$
\begin{aligned}
& \left(\begin{array}{l}
\Delta \mathrm{wbt} \\
\Delta \mathrm{wlt}_{\mathrm{lt}} \\
\Delta \mathrm{LP} \mathrm{Pt}_{\mathrm{bt}} \\
\Delta \mathrm{LP}_{\mathrm{lt}} \\
\Delta \mathrm{LP}_{\mathrm{pt}} \\
\Delta \mathrm{LE}_{\mathrm{t}}
\end{array}\right)=\left(\begin{array}{llllll}
\gamma_{1,11} & \gamma_{1,12} & \gamma_{1,13} & \gamma_{1,14} & \gamma_{1,15} & \gamma_{1,16} \\
\gamma_{1,21} & \gamma_{1,22} & \gamma_{1,23} & \gamma_{1,24} & \gamma_{1,25} & \gamma_{1,26} \\
\gamma_{1,31} & \gamma_{1,32} & \gamma_{1,33} & \gamma_{1,34} & \gamma_{1,35} & \gamma_{1,36} \\
\gamma_{1,41} & \gamma_{1,42} & \gamma_{1,43} & \gamma_{1,44} & \gamma_{1,45} & \gamma_{1,46} \\
\gamma_{1,51} & \gamma_{1,52} & \gamma_{1,53} & \gamma_{1,54} & \gamma_{1,55} & \gamma_{1,56} \\
\gamma_{1,61} & \gamma_{1,62} & \gamma_{1,63} & \gamma_{1,64} & \gamma_{1,65} & \gamma_{1,66}
\end{array}\right)\left(\begin{array}{l}
\Delta \mathrm{wbt}-1 \\
\Delta \mathrm{wlt}_{\mathrm{lt}-1} \\
\Delta \mathrm{LP}_{\mathrm{bt}-1} \\
\Delta \mathrm{LP}_{\mathrm{ftt}-1} \\
\Delta \mathrm{LP}_{\mathrm{pt}-1} \\
\Delta \mathrm{LREt}_{\mathrm{t}-1}
\end{array}\right) \\
& +\left(\begin{array}{lll}
\alpha_{11} & \alpha_{12} & \alpha_{13} \\
\alpha_{21} & \alpha_{22} & \alpha_{23} \\
\alpha_{31} & \alpha_{32} & \alpha_{33} \\
\alpha_{41} & \alpha_{42} & \alpha_{43} \\
\alpha_{51} & \alpha_{52} & \alpha_{53} \\
\alpha_{61} & \alpha_{62} & \alpha_{63}
\end{array}\right)\left(\begin{array}{llllllll}
\beta_{11} & \beta_{12} & \beta_{13} & \beta_{14} & \beta_{15} & \beta_{16} & c_{1} \\
\beta_{21} & \beta_{22} & \beta_{32} & \beta_{42} & \beta_{52} & \beta_{62} & c_{2} \\
\beta_{31} & \beta_{32} & \beta_{33} & \beta_{34} & \beta_{35} & \beta_{36} & c_{3}
\end{array}\right)\left(\begin{array}{l}
\text { Wbt -1 } \\
w_{t-1} \\
L P b t-1 \\
L P_{t t-1} \\
L P_{p t-1} \\
L R E_{t-1} \\
1
\end{array}\right)+\left(\begin{array}{l}
e_{1 t} \\
e_{2 t} \\
e_{3 t} \\
e_{4 t} \\
e_{5 t} \\
e_{6 t}
\end{array}\right)
\end{aligned}
$$

\footnotetext{
${ }^{11}$ Imposing (r-1) restrictions and normalising does not change the likelihood function, so no testing is involved in this case.

${ }^{12}$ Several simulation studies have shown that the size distortion of the asymptotic likelihood ratio tests for hypothesis testing on the cointegration vectors can be considerable in small samples (Johansen, 2000; and Gredenhoff and Jacobson, 2001). Gredenhoff and Jacobson (2001) suggested the use of bootstrapping techniques, while Johansen (2000) suggested the use of Barlett corrections to reduce size distortions. A conservative alternative is to reduce the level of significance, which is similar to the traditional adjustment method found, for instance, in Reimers (1992). In this paper, as the sample period is relatively small all tests are carried out using the 1 per cent level of significance.
} 
As mentioned previously, the estimation of the VECM in (7), subject to the rank restriction on the long-run matrix $\Pi$, does not generally determine a unique set of cointegrating relationships. In fact, the structural estimation of the cointegrating relationships requires the imposition of at least $r$ restrictions on each vector. Taking into account the results obtained in the previous section, we have therefore tested the following hypothesis on the full cointegration structure:

$$
\mathrm{H}_{0}: \beta^{\prime} Y_{\mathrm{t}}=\left(\begin{array}{ccccccc}
1 & 0 & \beta_{13} & \beta_{14} & \beta_{15} & \beta_{16} & \beta_{17} \\
0 & 1 & \beta_{23} & \beta_{24} & \beta_{25} & \beta_{26} & \beta_{27} \\
0 & 0 & 1 & \beta_{34} & \beta_{35} & 0 & \beta_{37}
\end{array}\right)\left(\begin{array}{l}
\text { Wbt } \\
\text { Wt } \\
L P_{b t} \\
L_{b t} \\
L P_{p t} \\
L R E t \\
1
\end{array}\right) \text { with } \beta_{23}+\beta_{24}+\beta_{25}=0 \text {, and }
$$

Following Johansen and Juselius (1994), the joint hypotheses $\mathrm{H}_{0}$ in (8) have been tested using the general hypothesis framework described in expression $(5)^{13}$. The likelihood ratio statistic of one over-identifying restriction was 3.24, which is well under the critical value at the 1 per cent level of significance $\left(\chi^{2}(1)=6.63\right)$. Thus, the hypothesis $\mathrm{H}_{0}$ cannot be rejected and the imposed restrictions have empirical support.

In the next step, and in order to be consistent with economic theory, symmetry has to be tested. Taking into account model (8), the symmetry hypothesis can be formulated as follows:

$$
\beta_{14}=\beta_{23}
$$

As this hypothesis includes cross-vector restrictions (involving coefficients from various cointegration vectors) the hypothesis was tested by the likelihood ration (LR) test procedure described in Pesaran and Shin (1999) and Doornik (1995). The LR statistic for jointly testing the restrictions imposed ${ }^{14}$ in (8) and (9), which is asymptotically distributed as $\chi^{2}(2)$ (the critical value is 9.21 at the 1 per cent significance level), was 5.47 suggesting that the symmetry restriction cannot be rejected. Table 5 reports the estimated $\beta$ parameters as well as their standard errors.

\footnotetext{
13 The restricted model is estimated using a switching algorithm of the type described in Johansen and Juselius (1992) and Mosconi (1993).

${ }^{14}$ In this case, the restricted model subject to non-linear restrictions is estimated using the non-linear switching algorithm in PcFiml version 9.0.
} 
Additionally, in this type of analysis it is also convenient to consider the estimated $\alpha_{i j}(i$ denotes the row and $\mathrm{j}$ the column) parameters, since they provide valuable information about the speed of adjustment of each variable towards the long-run equilibrium. The estimated $\alpha$ coefficients and their t-values are also shown in Table 5. The adjustment coefficients $\alpha_{12}$ and $\alpha_{21}$ are not significant, indicating that there are no feed-back effects onto beef (lamb) consumption from a deviation from the long-run equilibrium level of lamb (beef) consumption. Moreover, there is no significant adjustment of either budget share to disequilibrium in prices. Finally, beef prices do not adjust significantly to changes in any cointegrating vector $\beta_{\mathrm{i}}$, implying that the price of beef could be considered as a driving variable (a common stochastic trend) in the system ${ }^{15}$.

\section{(Insert Table 5)}

The last step in the long-run structural analysis is the economic interpretation of the estimated parameters. Johansen (1995b: 50) points out that "the coefficients on the cointegrating relation cannot usually be interpreted as elasticities, even if the variables are in logs, since a shock to one variable implies a shock to all variables in the long run, and hence the coefficients do not in general allow a ceteris paribus interpretation". Therefore, the dynamic properties of cointegrated VAR systems, as well as the long-run elasticities, can be better understood by analysing the Moving Average Representation (MAR) of the process. In the next section we discuss how to impose the identified restrictions on the short-run parameters and how long-run elasticities can be derived directly from the estimates of $\alpha, \beta$, and $\Gamma$.

\subsection{Short-Run Dynamics}

Once the VECM has been estimated, impulse response functions can be computed from the so-called MAR. These functions show the response of each variable in the system to a shock in any of the other variables. For food demand, it seems most interesting to analyse the short-

\footnotetext{
15 A joint test has been carried out to check whether all non-significant parameters were zero. The results indicated that the null hypothesis could not be rejected with a p-value of 0.054 .
} 
run dynamics of price and expenditure elasticities and how they converge to a long-run equilibrium.

The main problem with impulse response functions is that the contemporaneous correlation among the innovations, $e_{t}$, makes it difficult to isolate the shocks from a single variable. To overcome this problem, the original innovation $\left(\mathrm{e}_{\mathrm{t}}\right)$ has to be converted into an orthogonal one $\left(V_{t}\right)$ such that the initial covariance matrix of innovations $(\Sigma)$ is transformed into the identity matrix. In many applications, the Cholesky decomposition is applied, imposing causal relationships among variables. However, in dealing with structural models such as demand systems, it seems more appropriate to use a structural VAR approach in error correction form (SVECM). The SVECM is obtained by pre-multiplying the reduced form of the VECM defined above (with all the long-run restrictions imposed) by a $6 \times 6 \mathrm{~A}_{0}$ matrix. The model, using matrix notation, is then:

$$
\mathrm{A}_{0} \Delta \mathrm{Y}_{\mathrm{t}}=\mathrm{A}_{1} \Delta \mathrm{Y}_{\mathrm{t}-1}+\mathrm{a}\left(\hat{\beta}^{\prime} \mathrm{Y}_{\mathrm{t}-1}\right)+\mathrm{V}_{\mathrm{t}}
$$

where $\mathrm{A}_{1}=\mathrm{A}_{0} \Gamma_{1} ; \mathrm{a}=\mathrm{A}_{0} \alpha ; \hat{\beta}$ are the estimated long-run parameters with restrictions imposed (reported in Table 6); and $\mathrm{V}_{\mathrm{t}}=\mathrm{A}_{0} \mathrm{e}_{\mathrm{t}} \sim$ iid $(0, \Omega)$ with $\Omega=\mathrm{A}_{0} \Sigma \mathrm{A}_{\mathrm{o}}^{\prime}$.

The $\mathrm{A}_{0}$ coefficients contain the contemporaneous links between all the endogenous variables in $\mathrm{Y}_{\mathrm{t}}$. The identification of the short-run model requires the introduction of some restrictions in the matrix $\mathrm{A}_{0}{ }^{16}$. In our case, exclusion restrictions imposed thus banning certain variables from the relationships. The identification process requires the matrix $\mathrm{A}_{0}$ to have unit values in the main diagonal after normalisation.

The following identification has been imposed:

$$
\mathrm{A}_{0}=\left(\begin{array}{ccrrrr}
1 & 0 & * & * & * & * \\
0 & 1 & * & * & * & * \\
0 & 0 & 1 & 0 & 0 & 0 \\
0 & 0 & * & 1 & 0 & 0 \\
0 & 0 & 0 & * & 1 & 0 \\
0 & 0 & 0 & 0 & 0 & 1
\end{array}\right)
$$

\footnotetext{
${ }^{16}$ To be identified, the model requires, at least, $\mathrm{k}(\mathrm{k}-1) / 2$ where $\mathrm{k}$ is the number of equations.
} 
The first two equations correspond to an AID system. The following three equations establish links among prices. In order to find a causal relationship between the three prices, some of the results mentioned above have been considered. We noted above that the beef price could be considered a driving variable in the system, while not being influenced by it $^{17}$. Second, following Swanson and Granger (1997) the partial correlation between beef and poultry, conditional on lamb, and between lamb and poultry, conditional on beef, are calculated. The first is 0.07 and non-significant, while the second is 0.3 and highly significant. Hence, the causal model assumed between prices is $\mathrm{LP}_{b} \rightarrow \mathrm{LP}_{\mathrm{p}} \rightarrow \mathrm{LP}_{1}$. The last equation takes into account that real meat expenditure is exogenous, since weak separability has been assumed all along for this study. The SVECM is estimated using the Full Information Maximum Likelihood procedure and over-identified restrictions are tested using a LR statistic. The null hypothesis is not rejected at the 1 per cent level ${ }^{18}$.

The MAR of (10) is given by:

$$
\mathrm{Y}_{\mathrm{t}}=\mathrm{C} \sum_{\mathrm{i}=1}^{\mathrm{t}} \mathrm{V}_{\mathrm{t}}+\mathrm{C} *(\mathrm{~L}) \mathrm{V}_{\mathrm{t}}+\mathrm{Y}_{0}
$$

where $C=\beta_{\perp}\left(\alpha_{\perp}^{\prime} \Gamma \beta_{\perp}\right)^{-1} \alpha_{\perp}^{\prime} A_{0}^{-1}$, and $\Gamma=\mathrm{I}-\Gamma_{1} ; \alpha_{\perp}$ and $\beta_{\perp}$ are $\mathrm{k} \times(\mathrm{k}-\mathrm{r})$ matrices which are orthogonal to matrices $\alpha$ and $\beta$ respectively; $\mathrm{C}^{*}(\mathrm{~L})$ is an infinite polynomial in the lag operator $\mathrm{L}$, and $\mathrm{Y}_{0}$ is a function of the initial value (see Johansen, 1995b and Hendry and Juselius, 2000).

$\mathrm{C}$ is the long-run impact matrix and measures the "final impulse response effect" of a shock to each of the variables on all other variables of the system. The estimated coefficients of the first two rows of matrix $\mathrm{C}$ are given in Table 6. Long-run elasticities are shown in Table $7^{19}$.

\footnotetext{
17 This is consistent from an economic point of view, since beef imports are relatively significant in relation to internal production while lamb and poultry are domestically produced.

${ }^{18} \mathrm{LR}=5.21$, while the 1 per cent critical value of $\chi^{2}(5)$ is 15.09 . The degrees of freedom are calculated as [k(k1)/2]-s, where $s$ is the number of estimated parameters.

${ }^{19}$ Given the non-stationarity of budget shares, the restricted intercept in (8) can be interpreted as the steady state values for the budget shares. In addition, they are close to average budget shares in the base year (1992). Then,
} 
(Insert Table 6 and Table 7)

Conditional expenditure elasticities show that beef and lamb are considered luxury products within the meat group, while poultry is clearly a necessity. This is consistent with the fact that lamb and beef are the more expensive meat products. All own-price elasticities are negative and inelastic, whereas beef and lamb are more elastic in the long run, as expected. Cross-price elasticities are positive and highly significant indicating a certain degree of substitution. However, it is interesting to note that poultry meat behaves as a complementary product for lamb in the long run.

Having specified a dynamic demand system, and once the MAR is obtained, the short-run behaviour of demand elasticities has been analysed by calculating the impulse response functions in order to check how they converge to the long-run equilibrium. As can be observed, there are some deviations in the short run (Figure 1). Although in the long run beef and lamb expenditure elasticities are quite similar, beef is much more elastic in the short run, which is consistent with the fact that beef prices are the highest for the three meat products considered in this study. Another interesting characteristic is that the demand for poultry is quite inelastic in the short run, becoming more elastic as longer periods are considered. In relation to own-price elasticities, in the short run the demand for lamb is relatively more elastic than for other meat products. In Tunisia, the consumption of lamb is directly linked to special occasions (mainly Ramadan and the religious lamb festival) in which it is expected that lamb consumption is price inelastic (it is consumed independently of its price). However, during the rest of the year, lamb is considered a luxurious product and thus it is not unrealistic to think that any shock in its price will have an elastic response in the short run. On the other hand, poultry is more elastic in the short run than beef. This is not a surprising result, since in the case of beef there is a range of quality as well as a corresponding range of prices. Thus, an increase in beef prices can lead to a higher demand for lower quality beef, with total beef consumption more or less remaining stable. Poultry is a more homogeneous product in which price changes can stimulate changes in the demand for other meats.

and following Pesaran and Shin (1999), elasticities are calculated using the estimated intercepts as an approximation of average budget shares for each good. 
Cross-price responses do not change substantially during the period analysed. In the very short run, only an increase in beef prices has a positive impact on the main substitute, lamb. The effect on the quantity of poultry consumed is very low. The same happens in the case of increasing lamb prices in relation to the demand for beef, although in this case poultry behaves as a substitute in the short run while becoming independent in the long run. Finally, changes in poultry prices have a more permanent effect on the demand for beef and lamb.

(Insert Figure 1)

\section{Concluding Remarks}

This paper deals with three questions that have generated discussion in recent years: how does one specify, estimate and interpret cointegrated demand systems? We have used the Johansen and Juselius approach to define and estimate an AID system. Contrary to common practice, this analysis explores the possibility that the cointegration rank in a VECM is higher than the number of theoretical equilibrium relationships derived from a partial economic model (such as the AID model).

The demand for meat in Tunisia is investigated. Taking into account previous studies on the separability of fish and meat products, three different meats are considered: beef, lamb and poultry. All variables are assumed to be endogenous and three cointegrating vectors are found, more vectors than the number of equations in the system. The first two vectors are identified as long-run AID equations, while in the third one some exclusion restrictions are imposed. It is generally difficult to interpret the long-run structural parameters. In this paper, impulse response analysis and hence, short run model identification, has been considered as a necessary step to compute long-run elasticities. These elasticities as well as short-run dynamics are jointly considered using the Moving Average Representation of the VECM.

Although the main contribution of the paper has to do with the chosen methodology, results from this study are also consistent with the current state of meat markets in Tunisia, and with the several studies on this topic carried out on this country. Although conditional elasticities are obtained in this paper, previous studies have also shown that meat products, as a group, 
behave as luxury items in relation to total food expenditure. This means that beef and lamb are highly food expenditure elastic. So, taking into account the expected Tunisian income growth, and assuming that food expenditure is going to increase at the same growth rate that income (as it has been the case in the last 10 years (Dhehibi,1998)), beef and lamb consumption will increase in the coming years. The removal of food subsidies will not affect such elasticities for two main reasons: 1) because meat subsidies were very low before 1986 and disappeared after that year; and 2) an indirect effect (due to price increases of, for instance, basic staples) is not expected, as in recent years meat consumption trends have stabilised despite subsidy reductions. Thus, elasticities obtained in this paper can be used for demand projections. Finally, results indicate that any policy affecting meat prices has a distinct impact in the short and long run. In the short run, beef is more inelastic than poultry, since beef has more price-quality options than poultry. In the long run, price elasticities are larger indicating that consumers take some time to react to price changes.

With respect to methodology, this paper provides a useful framework for analysing cointegrated demand systems. Until now, in many empirical analyses, cointegration has been used only as an econometric tool where, as suggested by Juselius (1999 p 260), “inference relies on many untested assumptions using test procedures that only make sense in isolation, but not in the full context of the empirical model". Accounting for this problem, the approach presented here can lead to more appropriately specified dynamic demand models, and provides a tool for an improved economic interpretation of results.

Unfortunately, this approach also has some limitations. For example, as the size of the model (the number of equations) increases, it is difficult to find any kind of convergence once the identifying restrictions are imposed. Happily, this methodology can be extended not only to other functional forms, but also to other non-stationarity cases (for instance, the combination of stationary and non-stationary variables or the combination of $\mathrm{I}(1)$ and $\mathrm{I}(2)$ variables or, finally, the inclusion of purely exogenous variables as advertising).

\section{References}

Anderson, G.J. and Blundell, R.W. (1983). Testing Restrictions in a Flexible Dynamic Demand System: An Application to Consumer's Expenditure in Canada. Review of Economics Studies, 50, 397-410.

Anderson, G.J., and Blundell, R.W. (1984). Consumer non-Durable in the U.K: A Dynamic Demand System. Economic Journal (Supplement 94), 35-44. 
Attfield, C.L.F. (1997). Estimating a Cointegrating Demand System. European Economic Review, 41, 6173.

Balcombe, K.G. and Davis, J.R. (1996). An Application to Cointegration Theory in the Estimation of the Almost Ideal Demand System for Food Consumption in Bulgaria. Agricultural Economics, 15:47-60.

Brown, T.M. (1952). Habit, Persistence and Lags in Consumer Behaviour. Econometrica, 20(3):355-371.

Chambers, M.J., Nowman, K., B. (1997). Forecasting with the Almost Ideal Demand System: Evidence from Some Alternative Dynamic Specifications. Applied Economics, 29, 935-943.

Deaton, A., Muellbauer, J. (1980). An Almost ideal demand system. American Economic Review, 70, 312-326.

Denbaly, M., Vroomen, H. (1993). Dynamic Fertilizer Nutrient Demands for Corn: A Cointegrated and Error-Correcting System. American Journal of Agricultural Economics, 75, 203-209.

Dhehibi, B. (1998). Análisis y Perspectivas de la Demanda de Productos Alimenticios en Túnez: Un Enfoque Dinámico. Tesis de Master of Science. Instituto Agronómico Mediterráneo de Zaragoza (Spain).

Doornik, J. (1995). Testing General Restrictions on the Cointegrating Space. Nuffield College, Oxford, UK. Mimeo.

Doornik, J. and Hansen, H. (1994). A Practical Test for Univariate and Multivariate Normality. Discussion paper, Nuffield College, Oxford.

Engle, R.F. y Granger, C.W.J. (1987). Cointegration and Error Correction: Representation, Estimation and Testing. Econometrica, 55: 251-276.

Fuglie, K.O., 1994. The Demand for Potatoes in Tunisia: Are They a Cereal Substitute? European Review of Agricultural Economics, 21, 277-286.

Godfrey, L.G. (1988). Misspecification Test in Econometrics. Cambridge University Press.

Gonzalo, J. (1994). Five Alternative Methods of Estimating Long-Run Equilibrium Relationships. Journal of Econometrics, 60: 203-233.

Gredenhoff, M. and Jacobson, T. (2001). Bootstrap Testing Linear Restrictions on Cointegrating Vectors. Journal of Business and Economic Statistics 19(1), 63-72.

Harris, R. (1995). Using Cointegration Analysis in Econometric Modelling. University of Portsmouth. Prentice Hall, Harvester Wheatsheaf. London.

Hendry, F. and Juselius, K. (2000). Explaining Cointegration Analysis: Part II. Department of Economics, University of Copenhagen, Denmark http://www.econ.ku.dk/okokj/.

Institut National de la Statistique. Several Years. Bulletin Mensuel de la Statistique. Ministère du Développement Economique. Tunis.

Institut National de la Statistique. Several Years. Enquête Nationale sur le Budget et la Consommation des Ménages. Ministère du Développement Economique. Tunis.

Johansen, S. (1988). Statistics Analysis of Cointegration Vectors. Journal of Economic Dynamics and Control 12: 231-254.

- (1995a). Identifying Restrictions of Linear Equations with Applications to Simultaneous Equations and Cointegration. Journal of Econometrics 69:111-132.

- (1995b). Likelihood-based Inference in Cointegrated Vector Autoregressive Models. Oxford: Oxford University Press.

-2000). A Bartlett Correction Factor for Tests on Cointegrating Relations. Econometric Theory 16, 740778. 
Johansen, S. and Juselius, K. (1992). Testing Structural Hypotheses in a Multivariate Cointegration Analysis of the PPP and the UIP for UK. Journal of Econometrics 53: 211-244.

- (1994). Identification of the Long-Run and the Short-Run Structure: An Application to the ISLM Model. Journal of Econometrics 63: 7-36.

Juselius, K. (1999). Models and relations in Economics and Econometrics. Journal of Economic Methodology 6(2): 259-290.

-(2000).The Cointegrated VAR Model: Econometric Methodology and Macroeconomic Applications. http://www.iue.it/ECO/courses/KJ-opt-1-2000.html

Kwiatkowski, D., Phillips, P., Schmidt, P. and Shin, Y. (1992). Testing the Null Hypothesis of Stationarity Against the Alternative of Unit Root. Journal of Econometrics 54: 159-178.

Lahiani, N. (1996). Analyse de la Substitution au Niveau de la Consommation des Huiles. Mémoire de Cycle de Spécialisation, INAT, Tunis.

Ministère de l'Agriculture. Several Years - Production, Exportation et Importation des Produits Agricoles: Cas des Viandes. Ministére de l'Agriculture, Tunis.

Moschini, G. (1998). The semi-flexible Almost Ideal demand system. European Economic review, 42: 349-364.

Mosconi, R. (1993). Analysis of Deterministic Trends in Cointegrated Systems, Paper Presented at ESEM'1993, Uppsasa, August 1993.

- (1998). MALCOLM: The Theory and Practice of Cointegration Analysis in RATS. Cafoscarina, Venezia (http://www.greta.it/malcolm).

Ng, S. (1995). Testing for Homogeneity in Demand Systems When the Regressors are Non-Stationary. Journal of Applied Econometrics, 10, 147-163.

Osterwald-Lenum, M. (1992). A Note with Quantiles of the Asymptotic Distribution of the ML Cointegration Rank Test Statistics. Oxford Bulletin of Economics and Statistics, 54: 461-472.

Park, J. (1992). Canonical Cointegrating Regressions. Econometrica, 60:119-144.

Pesaran, M.H. and Shin, Y. (1999). Long-Run Structural Modelling. DAE Working Papers, University of Cambridge. http://www.econ.cam.ac.uk/faculty/pesaran.

Phillips, P.C.B., and Hansen, B.E. (1990). Statistical Inference in Instrumental Variables Regression with I(1) Processes. Review of Economic Studies, 57: 99-125.

Reimers, H.E. (1992). Comparisons of Tests for Multivariate Cointegration. Statistical Papers, 33: 335359.

Stock, J.H., and Watson, M.W. (1993). A Simple Estimator of Cointegrating Vectors in Higher Order Integrated System. Econometrica, 61: 783-820.

Swanson, R. and Granger, C.W.J. (1997). Impulse response Functions Based on a Causal Approach to Residual Orthogonalization in Vector Autoregressions. Journal of the American Statistical Association, Vol(92):357-367.

Tiao, G.C., and Box, G. E. (1981). Modelling Multiple Time Series Applications. Journal of American Statistical Association, 76: 802-816. 
Table 1. Evolution of Meat Consumption in Tunisia (kg/capita/year).

\begin{tabular}{llllllll}
\hline Meat Products & 1973 & 1975 & 1980 & 1985 & 1990 & 1995 & 1998 \\
Beef & 5.10 & 6.08 & 5.11 & 5.94 & 5.81 & 6.4 & 6.79 \\
Lamb & 5.25 & 5.75 & 5.19 & 5.34 & 4.95 & 5.33 & 5.8 \\
Poultry & 2.5 & 3.25 & 6.48 & 5.73 & 5.68 & 6.41 & 6.94 \\
\hline
\end{tabular}

Source: Ministère de l'Agriculture, Tunisia (several years).

Table 2. Results of Unit Root Tests.

\begin{tabular}{llllllllll}
\hline Series $^{\mathrm{a}}$ & Model $^{\mathrm{b}}$ & Lags & $\mathrm{t}_{\text {-test }}$ & $\mathrm{LM}(1)^{\mathrm{d}}$ & Series & Model & lags & t-test & $\mathrm{LM}(1)$ \\
\hline $\mathrm{w}_{\mathrm{l}}$ & $\tau$ & 0 & -0.07 & 1.29 & $\Delta \mathrm{w}_{1}$ & $\tau$ & 0 & -6.07 & 1.43 \\
$\mathrm{w}_{\mathrm{b}}$ & $\tau$ & 0 & -0.21 & 0.05 & $\Delta \mathrm{w}_{\mathrm{b}}$ & $\tau$ & 0 & -5.01 & 1.30 \\
$\mathrm{w}_{\mathrm{p}}$ & $\tau$ & 0 & -0.42 & 1.45 & $\Delta \mathrm{w}_{\mathrm{p}}$ & $\tau$ & 0 & -6.27 & 1.15 \\
$\mathrm{LP}_{1}$ & $\tau_{\tau}$ & 0 & -0.43 & 0.29 & $\Delta \mathrm{LP}_{1}$ & $\tau_{\mu}$ & 0 & -4.40 & 0.72 \\
$\mathrm{LP}_{\mathrm{b}}$ & $\tau_{\tau}$ & 0 & -2.62 & 3.14 & $\Delta \mathrm{LP}_{\mathrm{b}}$ & $\tau_{\mu}$ & 0 & -3.81 & 0.30 \\
$\mathrm{LP}_{\mathrm{p}}$ & $\tau_{\tau}$ & 1 & -2.94 & 2.81 & $\Delta \mathrm{LP}$ & $\tau_{\mu}$ & 0 & -3.94 & 0.19 \\
$\mathrm{LRE}$ & $\tau_{\mu}$ & 1 & -2.66 & 1.28 & $\Delta \mathrm{LRE}$ & $\tau$ & 0 & -4.86 & 2.45
\end{tabular}

${ }^{\mathrm{a}} \mathrm{W}_{\mathrm{i}}$ are budget shares where 1 =lamb; $\mathrm{b}=$ beef; and $\mathrm{p}=$ =poultry; $\mathrm{LP}_{\mathrm{i}}$ are prices expressed in $\log$ terms; LRE is the $\log$ of the real expenditure for meat.

${ }^{\mathrm{b}}$ Model $\tau_{\tau}$ indicates that the Dickey-Fuller regression contains a constant and a trend; $\tau_{\mu}$ indicates that only a constant is included; $\tau$ indicates that no deterministic components are included.

${ }^{\mathrm{c}}$ Critical values at the $5 \%$ level of significance are: $\tau_{\tau}=-3.60 ; \tau_{\mu}=-3.00$; and $\tau=-1.95$.

${ }^{\mathrm{d}}$ LM (1) is the Breusch-Godfrey Lagrange Multiplier statistic, used to test for autocorrelation of the first order. The critical value at the $5 \%$ level of significance is 3.84 .

Table 3. Results from Cointegration Rank Tests.

\begin{tabular}{lllllll}
\hline Eigenvalues & $\mathrm{R}$ & $\mathrm{p}-\mathrm{r}$ & $\lambda$-max & Critical value $(95 \%)^{\mathrm{a}}$ & Trace & Critical value $(95 \%)^{\mathrm{a}}$ \\
\hline 0.913 & 0 & 6 & 58.59 & 40.30 & 167.25 & 102.14 \\
0.816 & 1 & 5 & 40.64 & 34.40 & 108.67 & 76.07 \\
0.748 & 2 & 4 & 33.13 & 28.14 & 68.03 & 53.12 \\
0.560 & 3 & 3 & 19.70 & 22.00 & 33.90 & 34.91 \\
0.356 & 4 & 2 & 10.57 & 15.67 & 15.20 & 19.96 \\
0.175 & 5 & 1 & 4.63 & 9.24 & 4.63 & 9.24 \\
\hline
\end{tabular}

a The critical values are taken from Osterwald-Lenum (1992). 
Table 4. Hypothesis restrictions tests on the cointegration vectors ${ }^{\mathrm{a}, \mathrm{b}}$

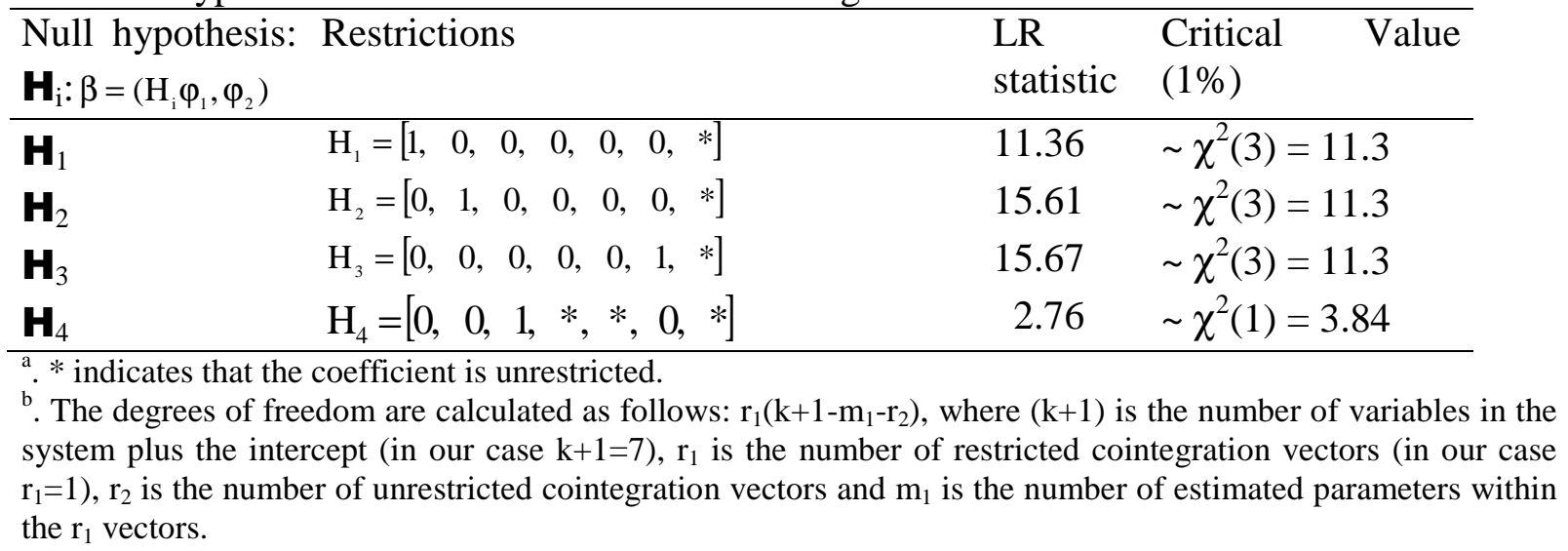

Table 5.Estimated $\beta^{\mathrm{a}}$ and $\alpha$ matrices under long-run structural identification

\begin{tabular}{lrrrrrrr}
\hline & $\mathrm{W}_{\mathrm{b}}$ & $\mathrm{W}_{\mathrm{l}}$ & $\mathrm{LP}_{\mathrm{b}}$ & $\mathrm{LP}_{1}$ & $\mathrm{LP}_{\mathrm{p}}$ & LRE & Constant \\
\hline$\hat{\beta}_{1}^{\prime}$ & 1 & 0 & -0.125 & 0.077 & 0.048 & -0.029 & -0.442 \\
$\hat{\beta}_{2}^{\prime}$ & & & $(.045)$ & $(.023)$ & $(.008)$ & $(.010)$ & $(.099)$ \\
$\hat{\beta}_{3}^{\prime}$ & 0 & 1 & 0.077 & -0.090 & 0.013 & -0.018 & -0.402 \\
& & & $(0.013)$ & $(0.015)$ & $(0.009)$ & $(.004)$ & $(0.077)$ \\
& & 0 & 1 & -0.768 & -0.431 & 0 & -0.710 \\
\hline $\mathrm{w}_{\mathrm{b}}$ & -1.16 & 0.709 & -0.17 & -2.65 & 0.24 & -1.37 & \\
$\Delta \mathrm{w}_{1}$ & -0.21 & -0.77 & -0.07 & -1.38 & -4.04 & -1.69 & \\
$\Delta \mathrm{LP} \mathrm{b}_{\mathrm{b}}$ & 0.24 & 0.49 & -0.15 & 0.98 & 1.43 & 0.76 & \\
$\Delta \mathrm{LP}$ & -0.87 & 0.29 & 0.27 & -2.73 & -1.86 & -2.66 & \\
$\Delta \mathrm{LP}$ & 0.77 & 1.21 & -0.29 & 2.87 & 2.16 & -1.72 & \\
$\Delta \mathrm{LRE}$ & -0.46 & -0.26 & 0.15 & -5.27 & -3.02 & 2.49 & \\
\hline
\end{tabular}

a. Standard error for $\beta$ are given in parentheses

Table 6. The first two estimated rows of the long-run impact matrix $C^{\text {a,b }}$

\begin{tabular}{lllllll}
\hline & $\sum \hat{\mathrm{V}}_{\mathrm{Wb}}$ & $\sum \hat{\mathrm{V}}_{\mathrm{Wl}}$ & $\sum \hat{\mathrm{V}}_{\mathrm{LP}_{\mathrm{b}}}$ & $\sum \hat{\mathrm{V}}_{\mathrm{LP}_{\mathrm{1}}}$ & $\sum \hat{\mathrm{V}}_{\mathrm{LP}_{\mathrm{p}}}$ & $\sum \hat{\mathrm{V}}_{\mathrm{LRE}}$ \\
\hline$\Delta \mathrm{W}_{\mathrm{b}}$ & 0.030 & -0.037 & 0.087 & -0.068 & 0.029 & 0.039 \\
& $(.021)$ & $(0.07)$ & $(.015)$ & $(.020)$ & $(.018)$ & $(.017)$ \\
$\Delta \mathrm{W}_{1}$ & -0.047 & 0.081 & -0.049 & 0.075 & -0.093 & 0.011 \\
& $(.024)$ & $(.043)$ & $(.024)$ & $(.039)$ & $(.038)$ & $(.008)$ \\
\hline
\end{tabular}

a. Standard-error are given in parentheses

b. Numbers given in this table corresponds to elements $C_{i j}$ which indicate the long-run impact of variable $\mathrm{j}$ on the beef and lamb budget shares. 
Table 7. Long-run Demand Elasticities for Meat in Tunisia.

\begin{tabular}{lllll}
\hline Meat products & Expenditure Elasticities & \multicolumn{3}{l}{ Price Elasticities $^{\mathbf{a}}$} \\
\cline { 3 - 5 } & & Beef & Lamb & Poultry \\
\hline Beef & 1.089 & -0.830 & 0.247 & 0.221 \\
& $(0.039)$ & $(0.051)$ & $(0.045)$ & $(0.040)$ \\
Lamb & 1.028 & 0.316 & -0.824 & -0.066 \\
& $(0.020)$ & $(0.058)$ & $(0.104)$ & $(0.095)$ \\
Poultry & 0.676 & 0.212 & 0.357 & -0.562 \\
& $(0.059)$ & $(0.024)$ & $(0.372)$ & $(0.383)$ \\
\hline
\end{tabular}

${ }^{\mathrm{a}}$ Marshallian own-price and Hicksian cross-price elasticities. 
Figure 1. Impulse response functions of meat demand elasticities in Tunisia

Shock in Beef price

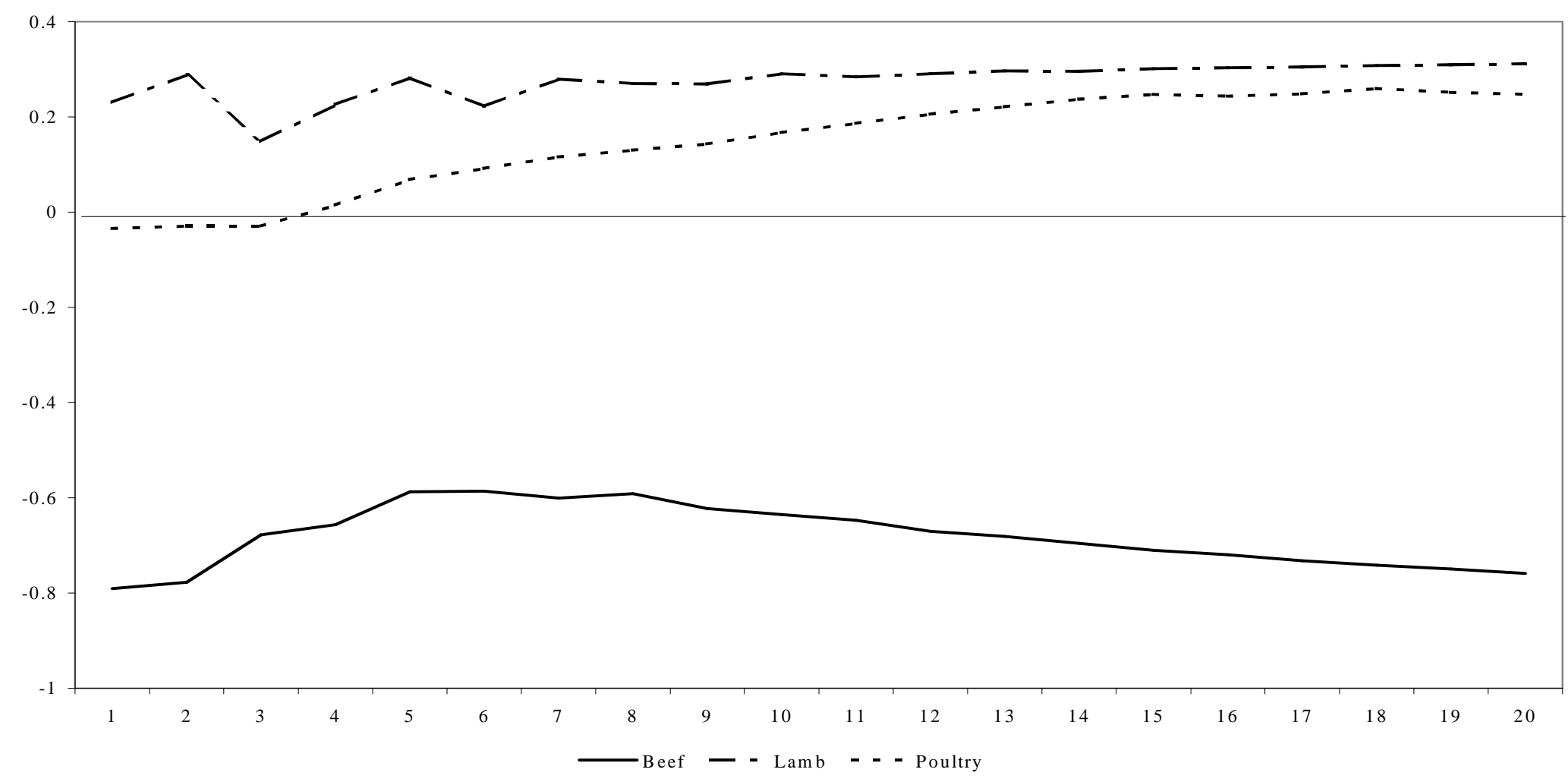


Shock in Lamb Price

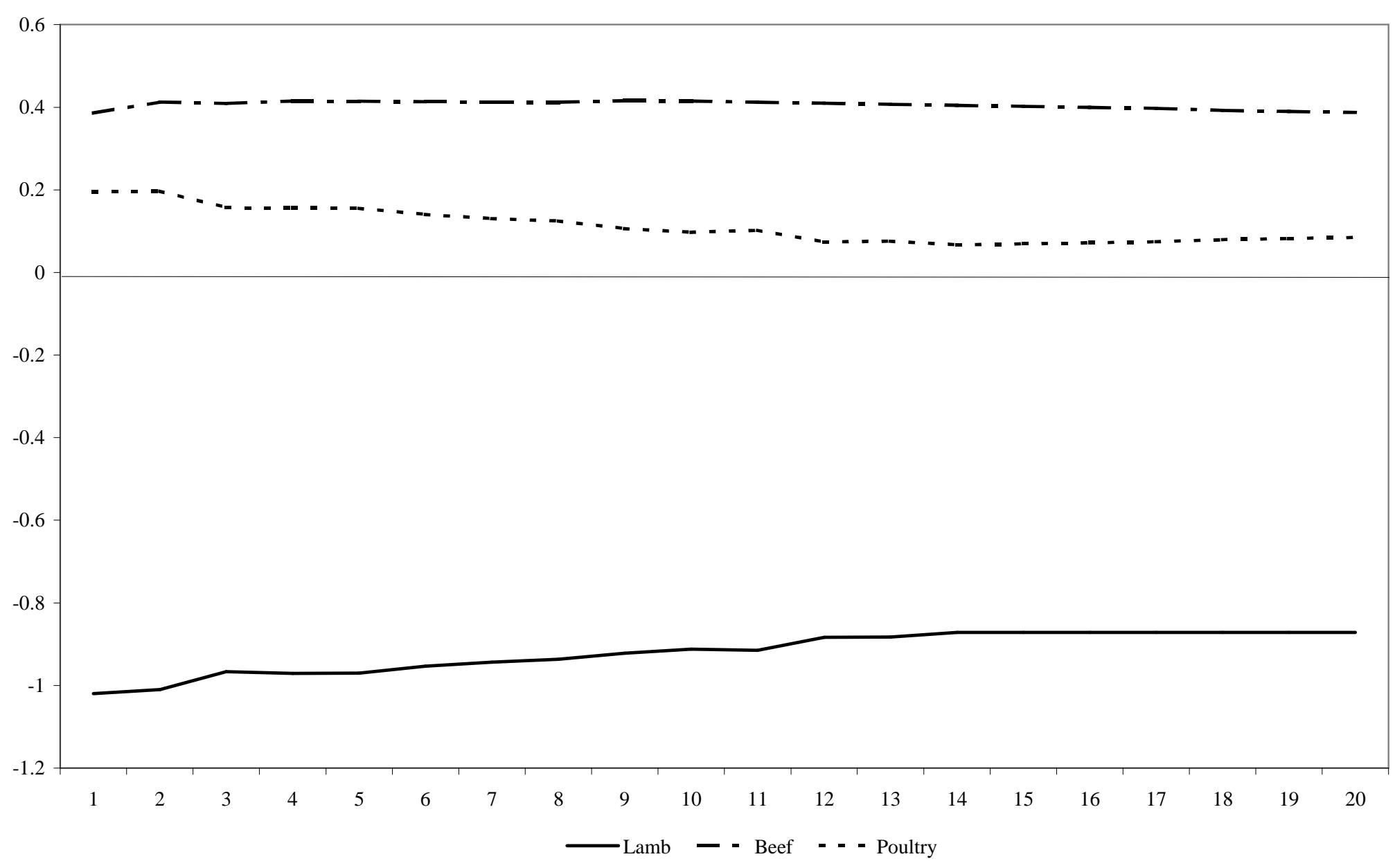


Shock in Poultry Price

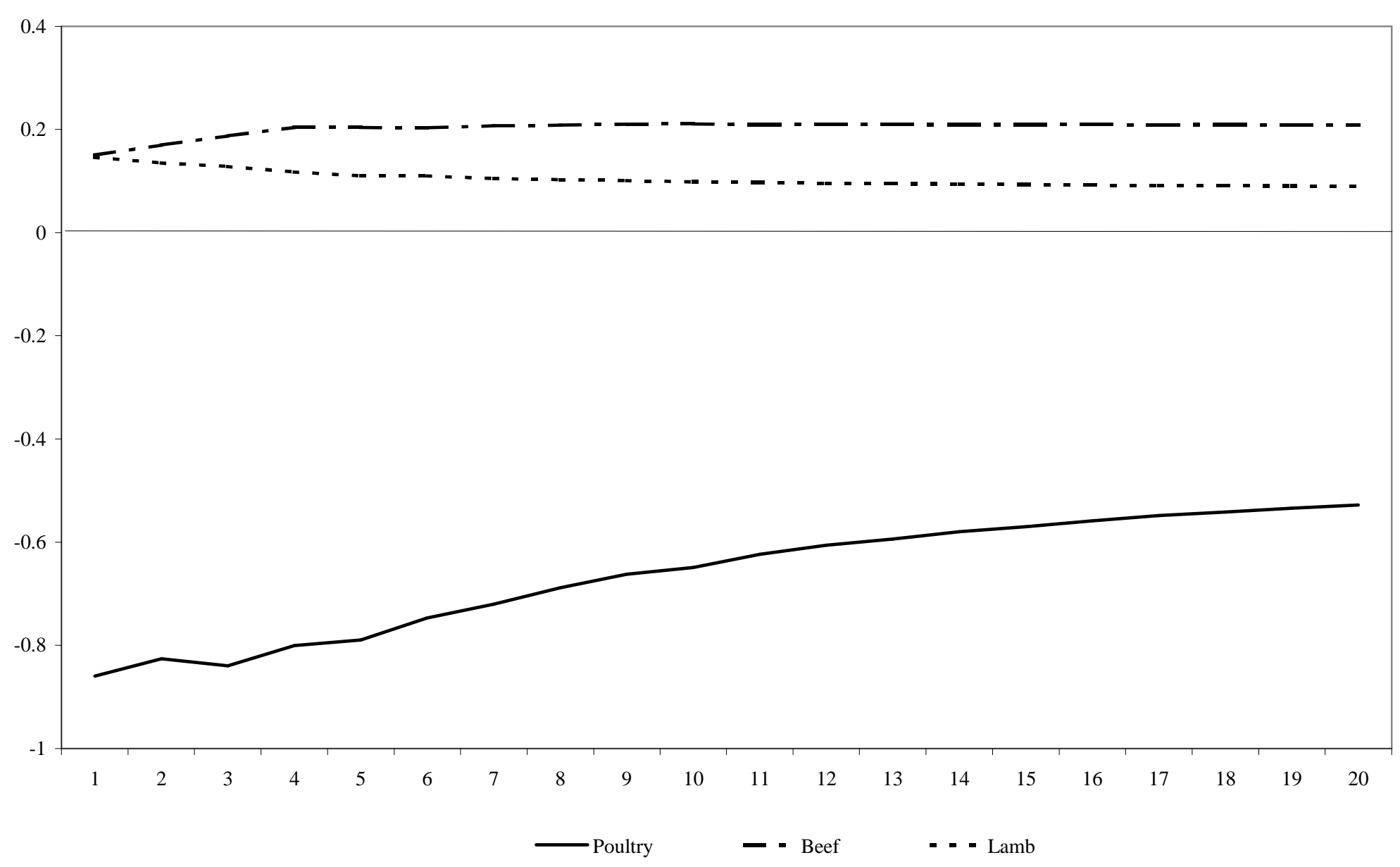


Shock in Real Expenditure

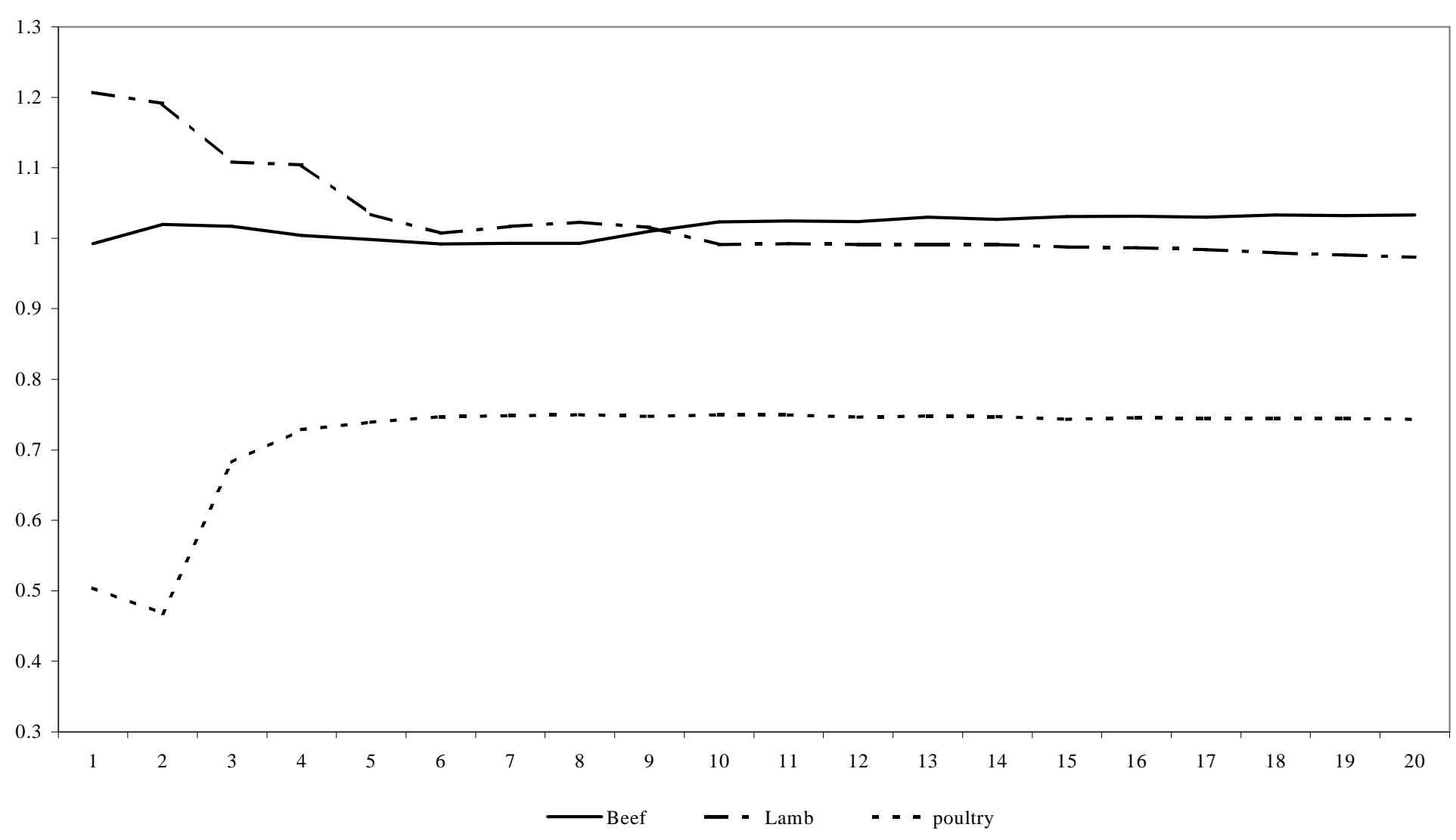

